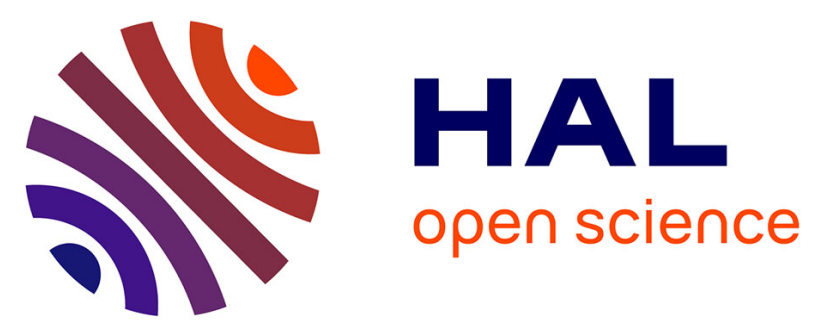

\title{
From Research to Operational Biomonitoring of Freshwaters: A Suggested Conceptual Framework and Practical Solutions
}

M. Lafont, C. Jézéquel, G. Tixier, J. Marsalek, A. Vivier, Pascal Breil, L. Schmitt, C. Poulard, P. Namour

\section{To cite this version:}

M. Lafont, C. Jézéquel, G. Tixier, J. Marsalek, A. Vivier, et al.. From Research to Operational Biomonitoring of Freshwaters: A Suggested Conceptual Framework and Practical Solutions. 4th International Scientific Conference BALWOIS 2010, on Water Observation \& Information System for Decision Support, May 2010, Ohrid, France. 11 p. hal-00562520

\author{
HAL Id: hal-00562520 \\ https://hal.science/hal-00562520
}

Submitted on 3 Feb 2011

HAL is a multi-disciplinary open access archive for the deposit and dissemination of scientific research documents, whether they are published or not. The documents may come from teaching and research institutions in France or abroad, or from public or private research centers.
L'archive ouverte pluridisciplinaire HAL, est destinée au dépôt et à la diffusion de documents scientifiques de niveau recherche, publiés ou non, émanant des établissements d'enseignement et de recherche français ou étrangers, des laboratoires publics ou privés. 


\title{
From Research to Operational Biomonitoring of Freshwaters: A Suggested Conceptual Framework and Practical Solutions
}

\author{
M. Lafont*, C. Jézéquel, G. Tixier, J. Marsalek, A. Vivier, P. Breil, L. Schmitt, C. Poulard, \\ Ph. Namour \\ * Cemagref, UR MALY, 3 bis quai Chauveau - CP 220, F-69336 Lyon, France \\ michel.lafont@cemagref.fr
}

\begin{abstract}
The conflicting needs of water managers (i.e., quick relevant operational responses) and ecologists (i.e., time consuming in-depth research) have been noted in freshwater biomonitoring and exist even today. To contribute to solving this dilemma, we are proposing a novel biomonitoring approach, which among many others, could be successfully used in this field and further developed in the future. In this approach, biomonitoring actions are integrated in conceptual schemes, in which hydrology, chemistry, hydrogeology and geomorphology bear as much importance as biology. Among biomonitoring tools, a harmonization system allows end-users to use a set of qualitative indicators, such as various biotic indices, and integrate the information given by individual biotic indices. Functional traits and calculation of an ecological potential in porous aquatic habitats, comprising surficial coarse sediments and the hyporheic system, are regarded as a basis for assessing ecological functioning of streams and rivers. This last methodology takes into account the dynamics of water exchanges between surface waters and groundwater. The objectives of ecological quality, ecological potentials and resilience capacity that need to be preserved or rehabilitated in aquatic habitats can be established. In lakes, a similar approach was followed and a general typology of lake functioning was proposed, including that for urban lakes and reservoirs. All those biomonitoring tools can be transferred to the end-users, but at the same time, these tools should be further researched and refined. Finally, this paper aims to promote practical high-tech tools, which are continually and interactively connected with the ongoing research.
\end{abstract}

Keywords: freshwater, biomonitoring approaches

\section{Introduction}

The first truly qualitative biological indices were developed by Kolkwitz and Marson (1909) (in Slàdečeck 1973) and the first "biotic indices", which were based on benthic macroinvertebrate assemblages, were presented by Woodivis (1960) in Great Britain and by Verneaux and Tufféry (1967) in France. These qualitative methodologies were relevant and well-suited for applications by end-users. They have served us well during the period when politicians, stake-holders and managers have become aware of the need to protect aquatic ecosystems against anthropogenic alterations. They also enabled quick and lasting advancement of research (R), research and development (R\&D), and development (D) projects in freshwater ecology. Facing the dramatic and growing alterations of freshwater ecosystems, the Water Framework Directive WFD (EU 2000) requested a good ecological status to be achieved for all European natural surface waters by the end of 2015. This urgent need has quickly amplified the conflicting demands of water managers (i.e., quick relevant operational responses) and ecologists (i.e., time consuming in-depth research). It has also encouraged the promotion of methods that are likely to be used by all member states (see Gabriels et al. 2010), which is, unfortunately, detrimental to other methods, particularly in the case of those developed by only one member country. Furthermore, when focusing on a single common approach, there is a risk that the valuable experience gained from the development and use of original (but still not widespread) methods will be completely lost. We are therefore suggesting that the conflicting demands of managers and ecologists can be reconciled in several ways (including the general approach presented here), which we are currently being developed on the basis of a multidisciplinary research and follow a general objective of sharing research findings with others. 


\section{Approaches applicable to running waters}

The approaches applicable to running waters were presented in several papers listed in Table 1. The conceptual pattern is given by the EASY concept (Ecological Ambience System), which is based on the idea that biocenoses (BIO) are not only related to the inputs of organic and mineral substances (IN), but also to the way such substances are stored and processed by the ecosystem. Thus, storage, assimilation and self-purification processes ("ecosystem defenses", ED) are likely to vary among different functional units (FUs) of the ecosystem.

Table 1. Concepts and tools developed for running waters.

EASY conceptual model (Lafont 2001)

It is intended for multidisciplinary studies and currently constitutes a conceptual basis for our ecohydrological research

$$
B I O=f(I N)-g(E D)
$$

BIO: biodiversity, including taxonomical richness and processes; IN: inputs; ED: ecosystem defenses

LOUE concept (Lowest Observed Urbanization Effects; Comprises a curve illustrating resilience, resistance, Lafont et al. 2008), integrated in resilience and and LOUE domains; suggestions of associated resistance domains biomonitoring tools for defining these domains and metrics for assessing the LOUE boundary (HS, FTrs;

Intended to define the limiting condition of the see below) ecosystem that must not be exceeded in urban aquatic habitats (i.e., the point of no return)

Harmonization System (HS) (Lafont 2001; Lafont et al. 2001; 2009)

Intended for the assessment of a global ecological status (or quality) at a given site and the targets (=compartments) that have to be rehabilitated, restored or preserved, even if the global ecological status is good; the true or suspected causes of physical and chemical alterations can be documented.

Integrates four components and their associated French standardized qualitative indices, harmonized by the five classes of ecological status (high, good, moderate, poor, bad, EU, 2000); a mean value is calculated but specific information given by each index is kept; a weighting procedure can be applied according to percent coverage of the river-bed by fine sediment (also referred to as the embeddedness); ecological damage assessment is defined by the loss of ecological status classes compared to the selected objective (high or good ecological status).

Ecohydrological approach (EA) (Vivier 2006; Lafont et al. 2006; 2009)

Intended for the assessment of the role of interactions between chemical and physical factors (mainly the dynamics of water exchanges between surface waters and groundwater) and their influence on biodiversity the FTrs characteristic for a preserved state of functioning to those of the most impaired ones.

Considerations for defining protection and rehabilitation Range of rehabilitation targets for urbanized streams strategies in urban aquatic systems (Breil et al. 2008)

Riverscape typology (Lenar-Matyas et al. 2009; Poulard et al. 2010, and this symposium)

Intended for finding engineering solutions providing both flood protection (dry emergency reservoirs, river training) and biodiversity preservation.
$\mathrm{EP}=[(\mathrm{FTr} 1+\mathrm{FTr} 2)+1] /[(\mathrm{FTr} 3+\mathrm{FTr} 4)+1]$, i.e. the ratio of and the associated metrics; guidance on "why", "what", "where" and "when" to monitor indicators for assessing aquatic ecosystems ("The 4 Ws strategy") calculation; FTrs are defined by oligochaete species assemblages from porous habitats (coarse surficial sediments, hyporheic system); FTrs reflect various physical and chemical factors that interact in the functioning of a stream;

Four riverscape types according to a gradient of increasing habitat richness, from fully artificial (manmade) beds to the natural ones; proposals of associated biomonitoring tools depending on the habitat richness (HS and EA, see above)

training) and biodiversity preservation. 
The structure of the conceptual model EASY illustrates the complexity of the physical, chemical and biological interactions in the receiving aquatic systems. This concept illustrates the interactions between mass flux (water and chemical substances), forms (geomorphology, physical structure of aquatic habitats in the riverscape) and biocenoses (all living organisms, from bacteria to fish). The LOUE (Lowest Observed Urban Effect, Tab. 1) is an adaptation of the EASY concept to urban aquatic habitats, and the "4Ws strategy" is a management strategy for ecological studies of such habitats. Consequently, we have adapted the existing qualitative biological methodologies (a qualitative approach) and created new ones (an ecohydrological approach) with the overall goal of contributing to solving the puzzle consisting of complex interactions linked to the healthy and sustainable functioning of the river system.

The qualitative approach is based on an examination of operational qualitative biotic indices (Harmonization System HS, Tab. 1). "Operational" means that the indices are standardized, or at least documented by reproducible field and laboratory protocols, have well-outlined ecological meaning and context and have been transferred to end-users for routine use. The HS was initially built with French indices (Lafont et al. 2009). The first component is named "the general ecological quality" and is expected to represent a general ability of the system to support biodiversity. Its related index includes all benthic invertebrate assemblages (The IBGN index, AFNOR 2004a or its successor for WFD compliance). The second component is "the biological quality of water" (the related index: diatom index IBD, AFNOR 2007). The third component is "the quality of fine sediments", recognizing that such sediments can store great quantities of pollutants (the related index: the oligochaete index IOBS, AFNOR 2002). The last component represents the "fish assemblages", recognizing that fish ecology is very different from that of other animals or vegetal biocenoses (the related index: the fish index IPR, AFNOR 2004b). It is expected that a general qualitative understanding of the river functioning can be gained by considering these four important compartments and by keeping the information given by individual indices intact, even if they produce conflicting information (Lafont et al. 2009).

The functional approach (functional traits; ecohydrological approach, EA). The functional traits were defined from oligochaete assemblages inhabiting porous habitats (i.e., surficial coarse sediments and the hyporheic system). The FTr1, "permeability", was obtained by measuring the proportion (\%) of oligochaete species which are indicators of active hydrologic exchanges between surface water and groundwater. The FTr2 is defined by the percentage of pollution-intolerant species, which are associated with good quality water. The FTr3 trait is defined by the percentage of water pollutiontolerant species. The FTr4 trait ("sludge effect") indicates the presence of polluted sludge (sediment) within the interstices of porous habitats and is associated with heavy pollution by urban and industrial discharges. The FTri trait is defined by the percentage of species which characterize moderately impacted conditions. The "Ecological Potential" EP is the ratio of FTrs characteristics of the most preserved habitats (FTr1 + FTr2) to those of the most impaired ones (FTr3 + FTr4). The FTrs and EP calculation are tools derived from the EASY concept and intended for the assessment of interactions between chemical and physical factors. These interactions mainly address the dynamics of water exchanges between surface waters and groundwater, which is a major factor for understanding stream functioning (Jones and Mulholland 2000).

The riverscape typology (EA approach) is intended to address technical solutions providing both flood protection and biodiversity preservation, and apply hydrology to issues concerning, e.g., building of dry flood protection reservoirs or river training (Lenar-Matyas et al. 2009; Poulard et al. 2010, and some papers presented at this symposium). It illustrates the known fact that biodiversity (including the related processes) is positively related to the habitat richness in the riverscape of the minor bed. The more the habitat richness is preserved or restored, the more the biodiversity will increase. However, the habitat richness in the riverscape has to follow the general geomorphologic pattern of the investigated sites, rather than trying to create habitats where none have previously existed. The riverscape typology was derived from an earlier approach developed for urban streams (Breil et al. 2008, Tab. 1).

\section{A selected approach to lacustrine waters}

We have formerly viewed the well-established eutrophication classification (oligotrophic, mesotrophic, or eutrophic lakes) as masking the fact that identically classified lakes strongly differed in other aspects: a eutrophic small lake or a eutrophic great alpine lake were considered sustaining the same 
trophic level (Lafont 1989; Lafont and Juget 1985; Lafont et al. 1991). Instead of taking a new look at the eutrophication concept, which was most relevant when considering phytoplankton and phosphorus contents, or building new qualitative indices, we have developed a new approach based on the study of oligochaete assemblages inhabiting sublittoral and deep lacustrine sediments (op. cited).

In small lakes, chemical inputs brought in with water interact with the physical properties of the lake, like the water volume and physico-chemical characteristics of sediments, and particularly their calcium carbonate contents (op. cited). The small size of a lake, and/or the abundance of coarse vegetal detritus (twigs, peat) or characeal algae are considered as factors impairing benthic colonization. In addition, $\mathrm{CaCO}_{3}$ was considered as an active agent of mineralization of organic matter in sediments; sediments poor in $\mathrm{CaCO}_{3}$ were generally rich in organic matter, which was consumed by invertebrates. There was an inverse relationship between oligochaete species richness and densities, and organic contents in sediments; the greatest oligochaete abundances were seen in sediments with the lowest organic and the highest $\mathrm{CaCO}_{3}$ contents (Lafont 1989; Lafont et al. 1991). This relationship was evident when comparing calcareous lakes with crystalline lakes, and when comparing lakes from strictly calcareous areas (Lafont 1989; Verneaux et al. 1988).

Several oligochaete indices were tested (Lafont 1989) and the IOBL index was recommended for practical applications (Juget et al. 1995 ; AFNOR 2005; Lafont 2007). This index is well suited for sediments in deep lakes (from 2-3 $\mathrm{m}$ to $>100 \mathrm{~m}$ depths) and is calculated as: $\mathrm{IOBL}=\mathrm{NSP}+3 \log _{10}$ $(\mathrm{N}+1)$, with NSP, the number of species in a sediment sample and $\mathrm{N}$, the densities of oligochaetes in the same sample per $0.1 \mathrm{~m}^{2}$. The index varies from 0 to $>20$ and is regarded as an indicator of the metabolic potential of sediments (e.g., the capacity of sediments for mineralizing organic matter). This capacity is activated by the levels of $\mathrm{CaCO}_{3}$ in the sediments. The metabolic potential was naturally higher in carbonate rich sediments of great alpine lakes $(I O B L>15)$ and the lowest in small peaty crystalline or calcareous lakes $(\mathrm{IOBL}<5)$.

Inputs of polluted sediments can alter the metabolic potential, but great lakes are naturally more resistant to pollution effects than the smaller ones. As it can be difficult to separate naturally low metabolic potentials and pollution effects, the concept of a "sensible species" factor was introduced to complement the diagnosis (Tab. 2). The list of sensible species is not fully transposable to running waters, because of great ecological differences that exist between ecosystems of running waters and lakes.

Table 2. Indicator oligochaete species in deep lake sediments; modified after Lafont (1989; 2007).

Group 1. "Sensible" species in deep lake sediments (= pollution-intolerant species)

Amphichaeta leydigii", Chaetogaster spp*., Nais spp., Ophidonais serpentina, Piguetiella blanci, Slavina appendiculata, Specaria josinae, Stylaria lacustris, Uncinais uncinata, Vejdovskyella intermedia, Bichaeta sanguinea, Stylodrilus spp., Dorydrilus michaelseni, Spirosperma velutinus, Rhyacodrilus falciformis, Psammoryctides barbatus, Marionina argentea

* these small-size species are generally not found in sediments sieved in the laboratory using a $0.5 \mathrm{~mm}$ mesh-size sieve, except for Chaetogaster diapahnus.

Group 2. Species, which if found alone, characterize a natural dystrophy (due to peat, coarse vegetal detritus, abundance of Characea)

Tubifex tubifex, Haemonais waldvogeli, Aulodrilus pluriseta, Vejdovskyella comata

Group 3. Species indicating high pollution effects, particularly when they are found alone in deep sediments

Potamothrix heuscheri, P. hammoniensis, Limnodrilus hoffmeisteri, L. claparedeanus, $L$. udekemianus, Lumbriculus variegatus, Bothrioneurum vejdovskyanum, Dero digitata

The IOBL index, which is associated with the percentage of sensible (pollution-intolerant) species present, allowed to establish a lake typology (Fig. 1; Tables 3 and 4; Lafont 1989; 2007). This typology was documented by considering oligochaete data from 50 lakes located in France (French Alpine and 
Jura areas) and other countries (Sweden, Nagell et al. 1977, USA, Howmiller 1974a; 1974b; Hungary, Lafont unpublished data; Finland, Särkkä 1972). Sediments from these lakes were sampled and sieved using a $0.500 \mathrm{~mm}$ mesh-size sieves. Where sensible species dominate, even though the metabolic potential is low, sediments have a very good functional status, but are not very productive (this was the case, for example, of Central Lake Michigan in the 1970s and Lake Konnevesi). Conversely, if these species are absent and the metabolic potential is very low, the lake is strongly polluted or naturally dystrophic. Generally, the species from groups 2 and 3 in Table 2 help distinguish between the pollution and dystrophy effects.

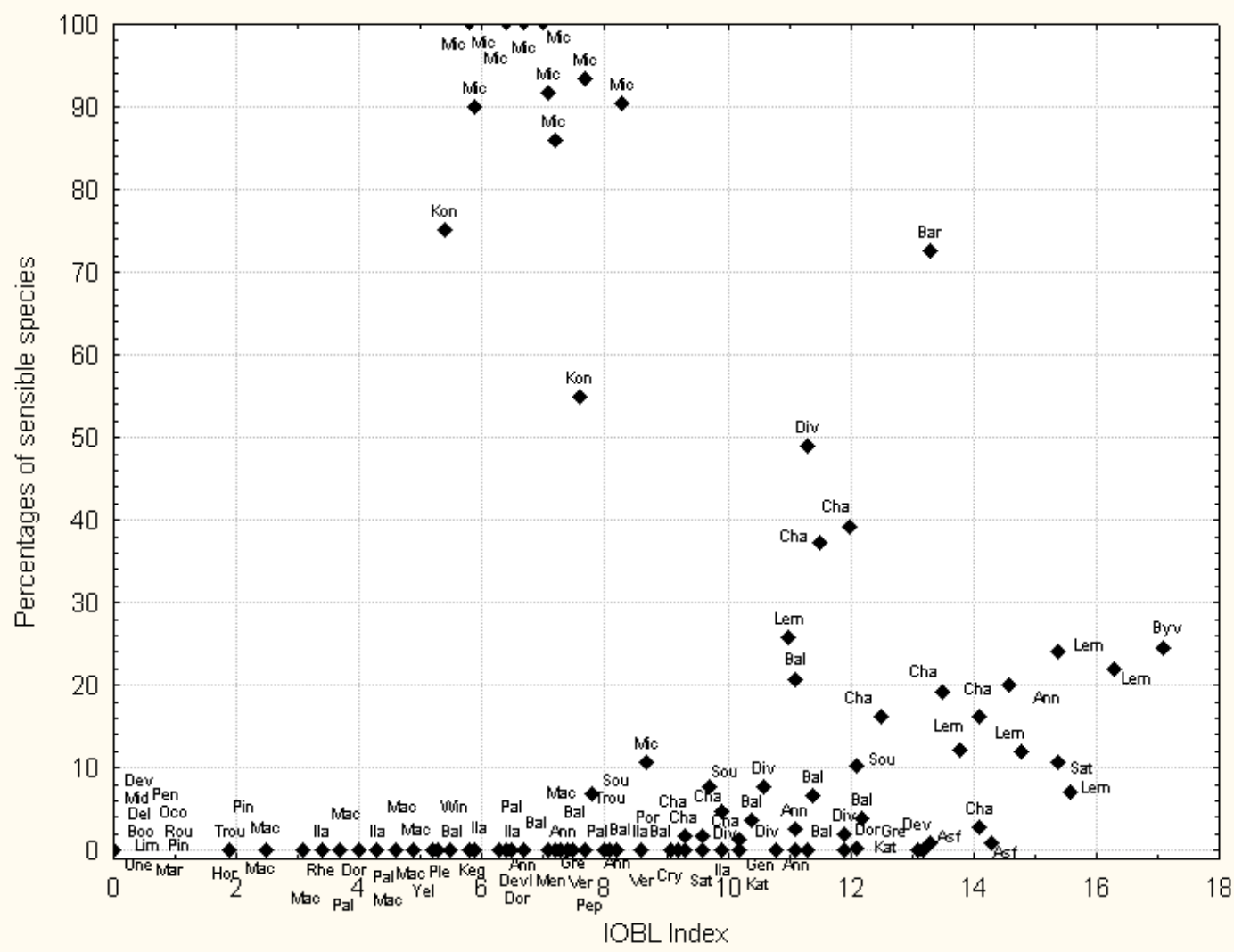

Figure 1. Deep sediments sampled from 50 lakes (115 surveys): IOBL index and percentages of sensible species. Abbreviations: Lem: Lake Léman; Cha: Lake Chalain (French Jura); Bal: Lake Balaton (Hungary), Mic: Central Lake Michigan; Lake Konnevesi (Finland).

Table 3. Classes of percentages of sensible (pollution-intolerant) species (SSp.) and the ecological status of deep lake sediments, after Lafont (2007).

\begin{tabular}{|l|c|l|}
\hline \multicolumn{2}{|c|}{ Classes of SSp. percentages } & \multicolumn{1}{c|}{ Comments } \\
\hline$>70 \% \ldots \ldots \ldots \ldots \ldots \ldots \ldots$ & 6 & High sediment quality (well preserved conditions) \\
\hline$>50 \%$ & 5 & Very good sediment quality \\
\hline $21-50 \%$ & 4 & Good sediment quality \\
\hline $11-20 \%$ & 3 & Moderate sediment quality \\
\hline $6-10 \%$ & 2 & Poor sediment quality (pollution or natural dystrophy) \\
\hline$\leq 5 \%$ & 1 & Bad sediment quality (pollution or natural dystrophy) \\
\hline
\end{tabular}

Note that the null potential $(\mathrm{IOBL}=0)$ may occur in natural lakes, for example in high-altitude mountain lakes or lakes with peaty or heavily polluted sediments, where no benthic organisms are found (Bazzanti and Lafont 1985; Collado and Schmelz 2001). 
Table 4. Typology of the metabolic potential of deep lake sediments, integrating the percentage classes of pollution-intolerant species.

\begin{tabular}{|ll|c|c|}
\hline \multicolumn{1}{|c|}{ Types of metabolic potential } & IOBL & Types \\
\hline 1A & Very strong potential (in great alpine lakes) & $>15$ & 1A6, 1A5, 1A4, 1A3, 1A2, 1A1 \\
\hline 1B & Strong potential : & $10,1 \leq 15$ & $1 \mathrm{~B} 6,1 \mathrm{~B} 5,1 \mathrm{~B} 4,1 \mathrm{~B} 3,1 \mathrm{~B} 2,1 \mathrm{~B} 1$ \\
\hline 2A & Moderate potential & $6,1 \leq 10$ & 2A6, 2A5, 2A4, 2A3, 2A2, 2A1 \\
\hline 2B & Low potential & $3,1 \leq 6$ & 2B6, 2B5, 2B4, 2B3, 2B2, 2B1 \\
\hline 3A & Very low potential & $\leq 3$ & $3 \mathrm{~A} 6,3 \mathrm{~A} 5,3 \mathrm{~A} 4,3 \mathrm{~A} 3,3 \mathrm{~A} 2,3 \mathrm{~A} 1$ \\
\hline 3B & Null potential (no oligochaetes) & 0 & 4 \\
\hline
\end{tabular}

A specific example of the use of this typology is given below for Lake Vänern (Fig. 2) using the data on oligochaete assemblages published by Nagell et al. (1977). Each inlet embayment of the lake is treated as a "specific lake". The percentage of sensible species is the first to respond to an increasing gradient of pollution. The metabolic potential of sediments is then altered in the second phase, when the pollution becomes moderate to strong. This example illustrates the complementary features of the IOBL index and percentages of sensible species which help gaining a good understanding of the functioning of the lake. When the metabolic potential of deep sediments starts to change, the system responds with a shift to a lower IOBL.

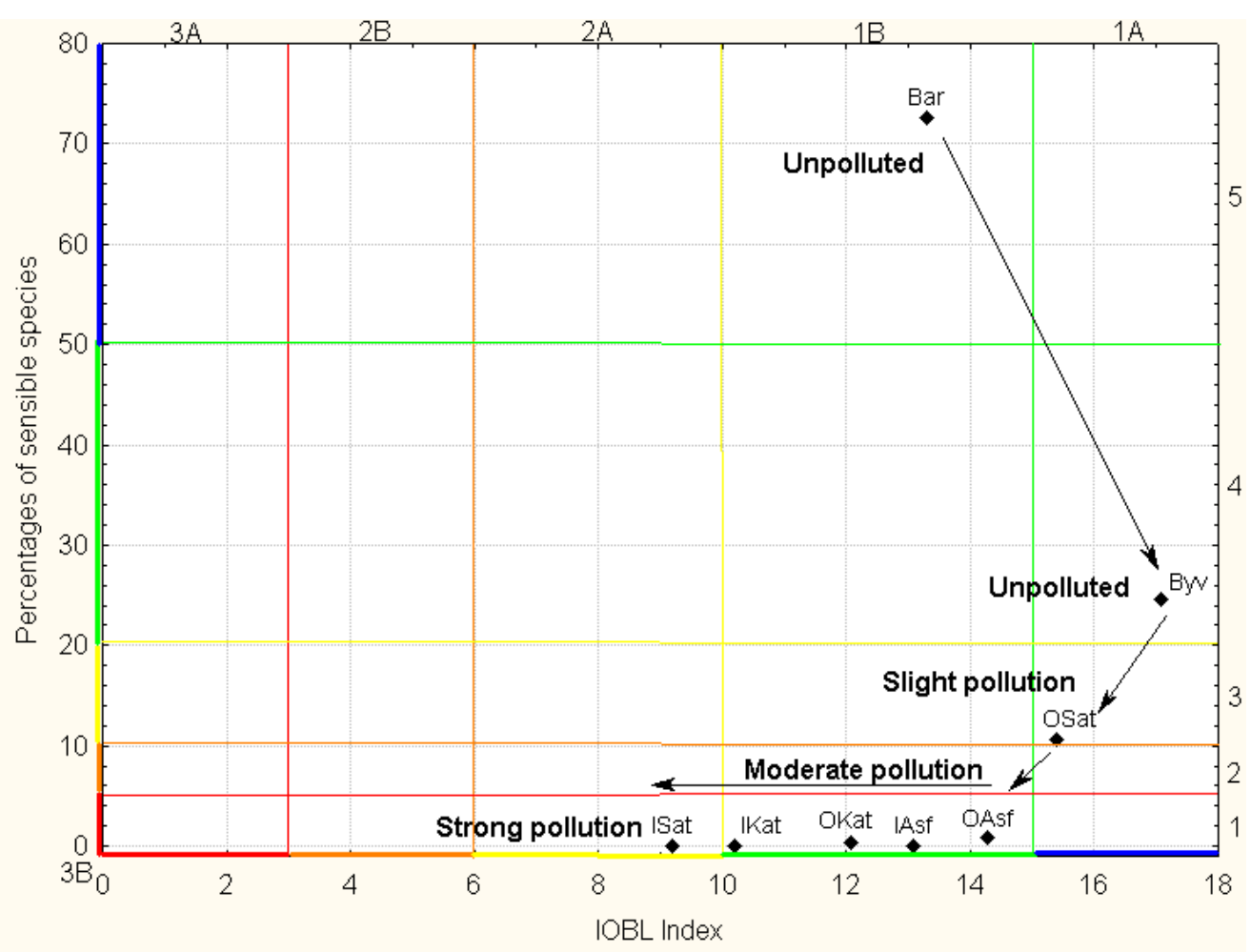

Figure 2. Conditions in various inlets of Lake Vänern (after Nagell et al. 1977): the IOBL index and percentages of sensible species.

The lake typology is also intended to define functional objectives to be restored or preserved in various types of lakes, including dam reservoirs. For example, in the case of Lake Vänern, an objective 1B might be selected for deep sediments (Fig. 2). With about $20-30 \%$ sensible species and the IOBL index values ranging from 10 to 12 , lake sediments functioning is preserved. With an IOBL > 12 and sensible species $>50 \%$, the deep sediments also sustain a very preserved functional status.

Urban lakes and stormwater facilities are mostly constructed systems, some of which originated from sandpits or were introduced to control surface runoff (see Marsalek et al. 2005). Some of these systems have been investigated in the Toronto region in Canada, and this work involved testing the IOBL (AFNOR 2005), with a modified protocol using the mesh size of $0.250 \mathrm{~mm}$ instead of $0.500 \mathrm{~mm}$ 
specified in the French AFNOR standard. Furthermore, the oligochaete metrics may be used both as a general stand-alone guideline, or be incorporated into Chapman's sediment triad approach (Tixier et al. ongoing research).

\section{Discussion and future prospects}

The discussion focuses on four promising approaches to ecological assessment followed by a summary of promising concepts, tools and future actions.

\section{Harmonization system (HS)}

The basic idea of the HS follows Chapman's sediment triad approach (Chapman 1992), which was developed as an innovative method consisting of three factors: sediment chemistry, sediment ecotoxicology, and benthic organisms. The HS can be further improved by testing its relevance on different datasets, and identifying its advantages and limitations, which were discussed earlier (Lafont et al. 2009). The benefits of the HS are evident, and as additional factors are defined, the precision of this method will increase. Two new factors are currently being incorporated: "eutrophication" (the related biomonitoring tool is the macrophyte index for rivers IBMR, AFNOR 2003) and the "porous matrix" (the related biomonitoring tool: FTrs and EP calculation, Lafont et al. 2009).

The HS was intended to integrate operational indices beyond those used in the French standards. We suggest that it is more productive to let ecologists use their own methodologies, from which they have gained great experience in their respective study areas, instead of asking them to switch to new methodologies, with which they have far less experience. The HS might be used for the intercalibration exercises required by the WFD (UE 2000), allowing each member state to keep their own methods, provided they are fully operational (i.e., well-documented ecological meaning, standardized or with reproducible protocols, and transferred to end-users for routine use). We furthermore state that it is necessary to assign great importance to the aquatic habitats that can physically store the pollutants (fine sediments and the porous matrix). The storage of pollutants can often mask the reality of the situation and lead to an optimistic view of the actual ecological situation when indices related to other components give high values for the ecological status. The storage of pollutants is an ecological time-bomb, because such pollutants can be released as conditions change.

\section{Ecohydrological approach (EA)}

The discussion of the EA approach with functional traits FTrs and ecological potential EP calculation was presented elsewhere (Lafont et al. 2009). The ongoing research focuses on the establishment of new FTrs and extension of the concept of FTr to other biocenoses beyond the oligochaetes. This process is already under way in the case of macrophyte assemblages (Trémolières, pers. com.). The FTrs were not conceived for assessing chemical or physical disturbances, but for integrating the effects of interactions between chemical and physical factors, in particular for the role of water exchanges between surface water and groundwater. In this case, the ecological status is abandoned and we try to understand which interactions between physical and chemical factors are important to support biodiversity. The notion of the ecological potential EP has to be reviewed by adding other elements than oligochaete assemblages. Both approaches, based on FTrs and riverscape typology, are integrated in the ecohydrological approach proposed by Zalewski (2006) and Zalewski and Wagner (2008). The conceptual frame is established by the EASY concept (Lafont 2001), and the role of hydrologic and geomorphologic factors is fully integrated (Schmitt et al. 2010).

Biodiversity includes processes, which have not been addressed, because we lack the knowledge of such aspects as microbial communities. The FTrs can only give a rough idea of these processes. The FTr4 for example represents a functional trait corresponding to the situation where metabolic processes are very active. Microcosm experiments in porous habitats contaminated by urban sewage showed that Tubificidae oligochaetes (=FTr4) were very efficient in activating bioturbation and metabolic processes (Datry et al. 2003; Mermillod-Blondin et al. 2003; Nogaro et al. 2006).

\section{Lake approach (LA)}

The LA was initially conceived for lake restoration purposes and was put forward as an alternative to the commonly used approach based on qualitative lake biotic indices (Wiederholm 1980; Milbrink et al. 2002; Rossaro et al. 2007; Beck and Hatch 2009; Gabriels et al. 2010). A very similar approach was 
developed by Verneaux et al. (2004) and Borderelle et al. (2008) (Lake biotic Index LBI). Moreover, these authors highlighted a concept of the "lake biogenic capacity", similar to the "metabolic potential", with a lacustrine index varying from 0 to 20 , which is similar to the IOBL index.

Furthermore, the IOBL index was originally intended to be integrated into a multi-disciplinary assessment (Lafont 1989), and is now integrated into Chapman's sediment quality triad in the case of urban lake studies (Tixier et al. ongoing research). Note in Figs. 1 and 2 that the LA allows integration of various biological or non-biological metrics, and can be recognized as an intermediate step between the harmonization system and the ecohydrological approach. It could be used for WFD intercalibration purposes, particularly for integrating different tools developed by others; this would still allow ecologists to use and develop their own tools. The typology was initially presented using smaller mesh-sizes for sieving $(0.250$ or $0.160 \mathrm{~mm}$; Lafont 1989$)$. A greater mesh-size $(0.500 \mathrm{~mm})$ was proposed later for applied studies, but recognizing that increasing the mesh-size leads to a loss of information (Tixier et al. ongoing research), the initial typology is preferred.

\section{Research management guidance}

We follow a multi-disciplinary perspective when considering what has to be developed or abandoned, and where research is needed or not (Table 5). It empowers us to optimize the organization of our multi-disciplinary research and to avoid possible "dispersion" of scientific activities. Future research should address sound practical adaptations for development by the way of R\&D, and such a development can yield new ideas for research directions. It means a research team has to bring together researchers, engineers, technicians, and ensure their collaboration in: (i) conducting research projects, (ii) establishing structural links with end-users from the public and private sectors and, (iii) contributing to minimizing the conflicting demands of water managers and ecologists by optimizing the role of stakeholders and reducing the time-lag between research and its application.

Table 5. Summary of concepts, associated tools and future actions. Legend: R: research; R\&D: research and development; D: development; HS: harmonization system; EA: ecohydrological approach; FTrs: functional traits; EP: ecological potential.

\begin{tabular}{|l|l|}
\hline \multicolumn{1}{|c|}{ Concepts and tools } & \multicolumn{1}{|c|}{ Needs } \\
\hline $\begin{array}{l}\text { HS (biological compartment } \\
\text { concept) }\end{array}$ & $\begin{array}{l}\text { D=R\&D; add other compartments (eutrophication, porous matrix); test on other } \\
\text { datasets; but no need for } R \text { on qualitative tools, only develop the integration of } \\
\text { functional tools }\end{array}$ \\
\hline EA (EASY concept, LOUE) & $\begin{array}{l}\text { R=R\&D>D; add other oligochaete FTrs and other living assemblages; ongoing } \\
\text { research on the role of interactions between physical and chemical factors; } \\
\text { improve the notion of EP; establish a numerical version of the EASY concept }\end{array}$ \\
\hline Riverscape concept & R\&D>D; test the methodology on various systems; refine the riverscape types \\
\hline Lake approach & $\begin{array}{l}\text { R=R\&D=D; add benthic and plankton data to the typology; need for R and R\&D in } \\
\text { reservoirs and urban lakes, including ecotoxicological research; need for routine } \\
\text { use of LA (D); consider smaller mesh-size sieving (0.250 or 0.160mm) }\end{array}$ \\
\hline
\end{tabular}

We have also developed a protocol for technology transfer (Table 6). It consists of six stages, and the last stage allows accelerating this cycle by initiating improvements, and generating new ideas and new research. In stage 3 , an official agreement for technology transfers might be signed with public or private end-users.

\section{General conclusions}

We finally suggest that using the existing operational tools encompassed in scientifically open typologies (HS, LA, LOUE, riverscapes) might save a significant amount of time in solving the problem of the conflicting needs of water managers and ecologists. For example, the recently developed ecohydrological approach employing FTrs and EP is already operational and available to other colleagues, even though the research in this field is still continuing. Furthermore, we claim that multidisciplinary research and development cannot be done without disciplinary excellence. A good 
way to unite various disciplines is to present a common conceptual framework, including a protocol for research management (Tables 5 and 6 ).

Table 6. Stages of technology transfer (modified after Vivier 2006).

\begin{tabular}{|c|l|}
\hline Stages & \multicolumn{1}{|c|}{ Needs } \\
\hline 1 & Research projects R; elaboration of scientific fundamentals and concepts; papers in scientific journals \\
\hline 2 & $\begin{array}{l}\text { Research \& Development (R\&D) projects and actions; testing of tools in various situations; papers in } \\
\text { scientific and technical journals }\end{array}$ \\
\hline 3 & $\begin{array}{l}\text { Research \& Development (R\&D); establishment of technical guidelines, standardization; convention of } \\
\text { technology transfer with end-users }\end{array}$ \\
\hline 4 & Development; training of end-users \\
\hline 5 & Development; checking of end-user results and their conformity to a quality control chart \\
\hline 6 & R, R\&D and D; experience return $\rightarrow$ improvements, new ideas, new research \\
\hline
\end{tabular}

We believe this top-down approach gives us the means to quickly acquire the most up-to-date tools, gives us the possibility to incorporate the older tools and allows us to fully benefit from the experience gained by other colleagues. We suggest that such an approach is beneficial during 'lean periods' of limited financial support for research and when there are urgent needs to quickly respond to water managers' demands. In agreement with the technology transfer protocol in Table 6 , it is possible to organize training sessions for those who need to learn new methodologies, integrate their own methodologies into a flexible conceptual frame, or incorporate some of the tools we proposed into their own conceptual frame.

\section{Acknowledgements}

The presented paper represents a synthesis of research findings produced in studies spanning many years. Such work has been supported by numerous funding providers and it is impossible to list them all without forgetting some.

\section{References}

AFNOR, 2002. Qualité de l'eau - Détermination de l'indice oligochètes de bioindication des sédiments (IOBS). Norme Française NF T 90-390.

AFNOR, 2003. Qualité de l'eau - Détermination de l'indice biologique macrophytique en rivière (IBMR). Norme Française NF T90-395.

AFNOR, 2004a. Essai des eaux: détermination de l'indice biologique global normalisé (IBGN). Norme française NF T 90-350.

AFNOR, 2004b. Qualité de l'eau - Détermination de l'indice poissons en rivière (IPR). Norme Française NF T 90-344.

AFNOR, 2005. Qualité de l'eau - Détermination de l'indice oligochètes de bioindication lacustre (IOBL). NF T90-391.

AFNOR, 2007. Détermination de l'Indice biologique Diatomées (IBD). Norme française NF T 90-354.

Bazzanti M. \& Lafont M., 1985. Variabilité des soies spermathécales de Potamothrix heuscheri (Bretscher) (Oligochaeta, Tubificidae) dans le lac de Nemi et remarques sur la relation entre cette espèce et le degré de trophie des lacs. Annls. Limnol., 2 : 107-115. 
Beck M.W., Hatch L.K., 2009. A review of research on the development of lake indices of biotic integrity. Environ. Rev., 17: 21-44.

Borderelle A.L., Gilmette C., Lovy C.,Gerdeaux D.\& Verneaux V., 2008. Macroinvertebrate $\delta^{13} C$ variability analysis for the assessment of lake trophic functioning. Fundamental and Applied Limnology, Archiv für Hydrobiologie, 172/4: 289-300.

Breil P., Lafont M., Fletcher T.D \& Roy A., 2008. Aquatic ecosystems. In: Fletcher T.D \& Deletić A. (Eds) Data Requirements for Integrated Urban Water Management, Chapter 20, Taylor \& Francis group, London: 259-272.

Chapman P.M., 1990. The sediment quality triad approach to determining pollution-induced degradation. The Science of the Total Environment, 97/98: 815-825.

Datry T., Hervant F., Malard F., Vitry L. \& Gibert J., 2003. Dynamics and adaptive responses of invertebrates to suboxia in contaminated sediments of a stormwater infiltration basin. Archiv für Hydrobiologie 156: 339-359.

Collado R., Schmelz M., 2001. Oligochaete distribution patterns in two German hardwater lakes of different trophic state. Limnologica: 317-328.

EU, 2000. Directive 2000/60/EC of the European Parliament and of the Council of 23 October 2000 establishing a framework for Community action in the field of water policy. Official Journal of the European Communities L327, 1-72.

Gabriels W., Lock K., De Pauw N., .Goethals P.L.M., 2009. Multimetric Macroinvertebrate Index Flanders (MMIF) for biological assessment of rivers and lakes in Flanders (Belgium). Limnologica (2009), doi:10.1016/j.limno.2009.10.001

Howmiller R.P., 1974a. Studies on aquatic Oligochaeta of inland waters of Wisconsin. Wisconsin Academy of Sciences, Arts and Letters, 62: 337-356.

Howmiller R.P., 1974b. Composition of the oligochaete fauna of central Lake Michigan. Proc. $17^{\text {th }}$ Conf. Great Lakes Res.: 589-592.

Jones J.B. and Mulholland P.J., 2000. Streams and ground waters. Academic Press, San Diego, $425 \mathrm{pp}$.

Juget, J., M. Lafont, J. Mouthon \& D. Gerdeaux, 1995. Structure des communautés benthiques et pisciaires. In: "Limnologie générale", R. Pourriot \& M. Meybeck, eds, Masson, Paris, Milan, Barcelone : 494-513.

Lafont M., 1989. Contribution à la gestion des eaux continentales: utilisation des oligochètes comme descripteurs de l'état biologique et du degré de pollution des eaux et des sédiments. Doctorat d'Etat ès Sciences, Université Lyon $1: 403$ pp.

Lafont M., 2001. A conceptual approach to the biomonitoring of freshwater: the Ecological Ambience System. Journal of Limnology (Suppl. 1) 60: 17-24.

Lafont M., 2007. Interprétation de l'indice lacustre oligochètes IOBL et son intégration dans un système d'évaluation de l'état écologique. Cemagref/MEDAD: 18 pp.

Lafont M., Juget J., 1985. Les Oligochètes de quelques lacs français: propositions en vue de leur utilisation pratique pour apprécier l'état biologique des sédiments profonds. Verh. Internat. Verein. Limnol., 22: 3019-3023.

Lafont M., Juget J. \& Rofes G., 1991. Un indice biologique lacustre basé sur l'examen des oligochètes. Rev. Sci. Eau, 4 : 253 - 268.

Lafont M., Vivier A., Nogueira S., Namour P. \& Breil P., 2006. Surface and hyporheic oligochaete assemblages in a French suburban stream. Hydrobiologia 564: 183-193.

Lafont M., L. Grapentine, Q. Rochfort, J. Marsalek, G. Tixier and P. Breil, 2007. Bioassessment of wet-weather pollution impacts on fine sediments in urban waters by benthic indices and the sediment quality triad. Wat. Sci. Tech., 56 (9) : 13-20.

Lafont M., Marsalek J. \& Breil P., 2008. Urban Aquatic Habitat characteristics and functioning. In: Wagner, I., Marsalek, J., Breil, P. [Eds.] Aquatic Habitats in Integrated Urban Water Management, Chapter 2. Urban water Series - UNESCO-IHP, Taylor and Francis Group, The Netherlands: 9-24. 
Lafont M, Jézéquel C., Vivier A., Breil P., Schmitt L., Bernoud S., 2009 (in press). Refinement of biomonitoring of urban water courses by combining descriptive and ecohydrological approaches. Ecohydrol. Hydrobiol. 9 (2), DOI: 10.2478/v10104-009-0047-3

Lenar-Matyas A., Lafon M., Lapuszek M., Poulard C., 2009. Alleviating effects of the technical training of mountainous rivers and streams in the urban areas. Infrastructure and Ecology of Rural Areas, Polish Academy of Sciences, Cracow Branch, Commission of Technical Infrastructure, 9: 241251 (in Polish language).

Marsalek J., Rochfort Q. \& Grapentine L., 2005. Aquatic habitat issues in urban stormwater management: challenges and potential solutions. Ecohydrology and Hydrobiology 5: 269-279.

Mermillod-Blondin F., Creuzé des Châtelliers M., Gérino M., 2003. Effects of the interaction between tubificid worms on the functioning of hyporheic sediments: an experimental study in sediment columns. Archiv für Hydrobiologie 156: 203-223.

Milbrink G., Timm T., Lundberg S., 2002. Indicative profundal oligochaete assemblages in selected small Swedish lakes. Hydrobiologia, 468: 53-61.

Nagell B., Landhal B.C.C \& Lann F.H., 1977. Quantitative and qualitative composition of bottom fauna in polluted parts of lake Vänern and some aspects of water quality indices. Vatten, 4: 434-441.

Poulard C., Lafont M., Lenar-Matyas A., Lapuszek M., 2010. Flood mitigation designs with respect to river ecosystem functions-A problem oriented conceptual approach. Ecological Engineering, 36: 6977.

Nogaro G., Mermillod-Blondin F., François-Carcaillet F., Gaudet J.P., Lafont M., Gibert J., 2006. Invertebrate bioturbation can reduce the clogging of sediment: an experimental study using infiltration sediment columns. Freshwater Biology 51: 1458-1473.

Rossaro B., Marziali L., Cardoso A.C., Solimini A., Free G., Giacchini R., 2007. A biotic index using macroinvertebrates for Italian lakes. Ecological Indicators, 7: 412-429.

Särkkä J., 1972. The bottom macrofauna of the oligotrophic lake Konnevesi, Finland. Ann. Zool. Fennici, 9 : 141-146.

Schmitt L., Lafont M., Trémolières M., Jézéquel C., Vivier A., Breil P., Namour P., Valin K., Valette L., 2010 (in press). Using hydro-geomorphological typologies in functional ecology: preliminary results in contrasted hydrosystems. Physics and Chemistry of the Earth, doi:10.1016/j.pce.2009.11.011

Slàdečeck V., 1973. System of water quality from the biological point of view. Arch. Hydrobiol. Beih., $7: 1-218$.

Verneaux J., Tufféry G., 1967. Une méthode zoologique pratique de détermination de la qualité biologique des eaux courantes. Indices biotiques. Ann. Sci. Univ. Besançon, Zool., 3: 79-90.

Verneaux J., Guyard A., Joly D., Vidonne A., 1987. Caractères généraux des sédiments de 10 lacs jurassiens. Sciences de l'Eau, 6: 107-128.

Verneaux, V., Verneaux, J., Schmitt, A., Lovy, C., \& Lambert, J.C., 2004. The Lake Biotic Index (LBI): an applied method for assessing the biological quality of lakes using macrobenthos; the Lake Châlain (French Jura) as an example. Ann. Limnol. - Int. J. Limnol., 40 : 1-9.

Vivier A. 2006. Effets écologiques de rejets urbains de temps de pluie sur deux cours d'eau périurbains de l'ouest lyonnais et un ruisseau phréatique en plaine d'Alsace. Thesis, L.P. University, Strasbourg, France: 208 pp.

Wiederholm T., 1980. Use of benthos in lake monitoring. JWPCF, 52: 537-547.

Woodivis F.S., 1964. The biological system of stream classification used by the Trent River Board. Chem. Ind., 14: 443-447.

Zalewski M., 2006. Ecohydrology-an interdisciplinary tool for integrated protection and management of water bodies. Archiv für Hydrobiologie, Supplementum 158/4: 613-622.

Zalewski M., Wagner I., 2008. Ecohydrology of urban aquatic ecosystems for healthy cities. In: Wagner, I., Marsalek, J., Breil, P. [Eds.] Aquatic Habitats in Integrated Urban Water Management, Chapter 6. Urban water Series - UNESCO-IHP, Taylor and Francis Group, The Netherlands, 95 -106. 